\title{
41
}

\section{Vögel (Mittelworträtsel)}

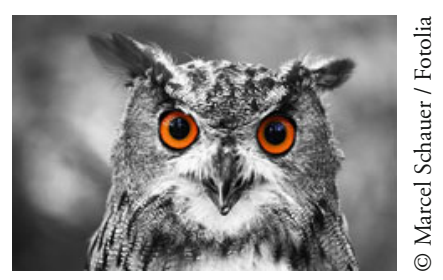

Suche in jeder Zeile das Wort, welches man links anfügen und rechts voransetzen kann, zum Beispiel SPRINGER - BUCH - FINK (s. u.). Die Buchstaben in den neun vorgegebenen Boxen ergeben - von oben nach unten gelesen das Lösungswort.

Tipp In jeder Zeile findet sich eine Vogelart.

\begin{tabular}{|c|c|c|}
\hline EIS & $\square---$ & HAUS \\
\hline WEIß & $-\square-$ & MEISE \\
\hline $\mathrm{NACHTI}$ & $\square---$ & WESPE \\
\hline HONIG & $--\square---$ & FRESSER \\
\hline KÖNIGS & $-\underline{\square}-$ & MEISE \\
\hline TIEF & $\underline{\square}-----$ & EULE \\
\hline SPRINGER & $\underline{\square}---$ & FINK \\
\hline FLUSS & $---\underline{\square}-$ & SCHWALBE \\
\hline $\mathrm{KIRSCH}$ & $---\underline{\square}$ & BEIßER \\
\hline GÄNSE & $\square---$ & HALS \\
\hline
\end{tabular}

Lösung:

(C) Springer-Verlag Berlin Heidelberg 2016

C. Reinbold, Fetthenne, Moderlieschen, Warzenbeißer,

DOI 10.1007/978-3-662-52817-4_41 